\title{
Students’ Perceptions of Service Learning in an Advanced Research Course
}

\author{
Stacy M. Deck \\ Laneshia Conner \\ Shannon Cambron
}

\begin{abstract}
Social work students are often anxious, apathetic, or resistant to learning research knowledge and skills. They may view research courses as irrelevant and disconnected from social work practice. Studies suggest that service-learning improves learning outcomes in social work research courses, but less is known about the processes through which these outcomes are achieved. This study explored the perceptions of 70 Masters-level social work students enrolled in an advanced research course that included a pro bono program evaluation of a shelter serving homeless men. Content analysis of students' narratives revealed three main themes. First, students perceived that they had changed their thinking about homelessness in positive ways. Second, students made connections between their research experience and the social work curriculum. Finally, an unanticipated theme of curriculum integration emerged. Critical reflection about a meaningful experience-an integral aspect of service-learning-supported students in developing metacognitive insight. This helped students to develop and apply social work research skills. The service-learning project supported students' mastery of other social work competencies and improved their integrated practice abilities. Because this approach is effective in helping students to embrace research and integrate it with social work practice, application and evaluation of service-learning are recommended for social work education.
\end{abstract}

Keywords: Service-learning; engaged teaching; social work; research competency; metacognition

Three decades ago, Epstein (1987) referred to social work students as "reluctants" and averred that "no other part of the social work curriculum has been so consistently received by students with as much groaning, moaning, eye-rolling, hyperventilation, and waiver strategizing as the research course” (p. 71). Notwithstanding calls in the ensuing decades to implement evidence-based practice (Gambrill, 1999; Thyer, 2004), and the profession's ongoing commitment to research-informed practice (Council on Social Work Education [CSWE], 2015; National Association of Social Workers, 2008), more recent contributions to the literature suggest that social work students remain anxious, apathetic, and resistant to learning research knowledge and skills (Harder, 2010; Kapp, 2006; Knee, 2002; Steinberg \& Vinjamuri, 2014). Importantly, some authors note that social work students see research courses as irrelevant and disconnected from social work practice (Harder, 2010; Hyde \& Meyer, 2004; Shannon, Kim, \& Robinson, 2012; Steinberg \& Vinjamuri, 2014). Therefore, it is unsurprising that social work practitioners' use of research-informed practice is inconsistent at best (Edmond, Megivern, Williams, Rochman, \& Howard, 2006),

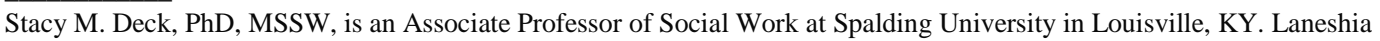
Conner, PhD, MSW, is an Assistant Professor in the School of Social Work at the University of North Carolina at Charlotte in Charlotte, NC. Shannon Cambron, EdD, MSW, is an Associate Professor of Social Work and BSSW Program Director at Spalding University in Louisville, KY. 
and that practitioners often lack the values and skills that underpin the use of research in practice (Shannon et al., 2012).

The shift from an emphasis on measuring course objectives to assessing professional competencies has sparked a challenge in higher education. In social work education specifically, this has required a deeper consideration of how to best activate learning that is aligned with CSWE research-related competencies. Emerging social work literature presents evidence that engaged and/or service-learning approaches improve learning outcomes in social work research courses by increasing students' motivation, knowledge, and skills (Anderson, 2000; Harder, 2010; Hyde \& Meyer, 2004; Kapp, 2006; Knee, 2002). Hands-on assignments and team-based work are described as essential for fostering learning that is interesting, authentic, and connected to the real world and students' own lived experiences (Harder, 2010; Hyde \& Meyer, 2004; Knee, 2002). Steinberg and Vinjamuri (2014) explain that this type of course design comes closest to Hardcastle and Bisman's (2003) "research as practice methodology" model for teaching research as contrasted with the "educated consumer of research" and the "practitioner scientist" models (p. 32).

Some assert that participation in actual research activities as a part of the social work curriculum increases the likelihood that students will use research in their future practice (Deck, Platt, \& McCord, 2015; Hyde \& Meyer, 2004; Kapp, 2006; Shannon et al., 2012). Kapp (2006) notes that gaining experience with conducting research in agencies, including exploring practice-related research and learning to design studies, develops skills that students will need in professional practice. While the connection between engaged and/or service-learning approaches and improved social work research course outcomes has been supported in the literature, less is known about the processes through which these outcomes are achieved.

\section{Literature Review}

\section{Adult Learning}

According to adult learning theory, adults who invest energy in the learning process on their own can weigh the pros and cons of learning versus not learning difficult content (Knowles, Holton, \& Swanson, 2005). The principles of andragogy provide insight into strategies for facilitating adult learning including incorporating life experiences, fostering responsibility for one's own learning, and employing a self-directed approach. Adults arrive at institutions of higher education with a myriad of life experiences and varied educational backgrounds. Differences in the amount and quality of those experiences increase the heterogeneity of adult learners.

Layne, Fields, Moyse-Steinberg, Krishna, and Dinov (2009) proposed five adult learning principles that help social work students learn and apply evidence-based practices: (a) relevance, (b) a problem-focused process, (c) scaffolding, (d) hands-on learning, and (e) engineered failure. Steinberg and Vinjamuri (2014) described the implications of these principles for social work research courses. In keeping with the relevance principle, the authors suggested that educators help students connect theory with practice experiences as 
well as their personal goals and values by engaging in a research process that begins with selecting a problem and ends with applying findings in practice. Problem-focused strategies are case-based with a focus on making meaning of evidence both conceptually and as a tool for research-based practice. The scaffolding principle suggests that students be given opportunities to think critically about varying perspectives and to synthesize new knowledge with their current practice approach. Hands-on learning (i.e., real-time application of evidence-based practice principles) and engineered failure (i.e., "opportunities to develop skills for contextually meaningful professional practice”) are critical to this process of integrating new perspectives, information, and skills (p. 372).

\section{Experiential Learning}

Kolb’s (1984) experiential learning theory proposed that learning is a transformative process of creating knowledge through experience. Kolb’s four-stage model cycles from concrete experience and reflective observation to abstract conceptualization and active experimentation. Hands-on learning provides an opportunity for learners to encounter tangible and transformative experiences.

To develop students' competency to respond to social concerns using best practices, experiential strategies should be employed across the social work curriculum (Campbell, 2012; Harder, 2010; Shannon et al., 2012; Wells, 2006). Intentional use of community engagement, active learning, and reflection is critical to professional skill development for effective practice. In pursuit of this, there is growing evidence that meaningful connections can be made between the social work knowledge base and effective practice by embedding service-learning throughout the curriculum including in research courses (Shannon et al., 2012).

As a form of experiential education, service-learning extends beyond the parameters of this approach (Campbell, 2012; Jacoby, 1996). Butin (2006) described service-learning as "an amalgam of ... experiential education, action research, critical theory, progressive education, adult education, social justice education, constructivism, community-based research, multicultural education, and undergraduate [and graduate-level] research" (p. 490).

\section{Service-Learning}

Bringle and Hatcher (1995) defined service-learning as "a credit-bearing educational experience in which students participate in an organized service activity that meets identified community needs and reflect on the service activity in such a way as to gain further understanding of course content, a broader appreciation of the discipline and an enhanced sense of civic responsibility” (p. 112). This seminal definition reflected the meaning of service-learning specified in the National and Community Service Act of 1990 (§12511), which explicitly describes service-learning as meeting community needs while enriching the academic curriculum. Thus, service-learning emphasizes systematic linkages between classroom experiences and service activities (Rhoads, 1998), it focuses on service as a means for learning (Averett \& Arnd-Caddigan, 2014), and it requires deliberate reciprocity among students, faculty, and community agencies (Phillips, 2011). Mutual 
responsibility, accountability, and benefits for all parties are emphasized (Hyde \& Meyer, 2004; Jacoby, 1996; Phillips, 2011).

The values of social justice and citizenship underpin service-learning (Donaldson \& Daughtery, 2011; Phillips, 2011). Phillips (2011) notes that "intentional, deep, and structured reflection... on the root causes of community problems, on the relationship between the service, community problems, and curriculum, and on the student's role in the service activity" distinguishes service-learning from mere volunteerism (p. 3). In addition to promoting reflection, service-learning fosters critical thinking and problem-solving (Cronley, Madden, Davis, \& Preble, 2014) and connects theory with practice experience (Kapp, 2006). Thus, service-learning is quite appropriate for social work education (Cronley et al., 2014; Robinson, Robinson, \& McCaskill, 2013; Rocha, 2000; Williams, King, \& Koob, 2002), aligns with its core values (e.g., service, justice, and the importance of human relationships) and the mission of the profession (Phillips, 2011), and emphasizes collaboration with clients and stakeholders (Robinson et al., 2013). Despite this goodnessof-fit, the social work profession lags behind other professions in its integration of and research on service-learning (Cronley et al., 2014; Phillips, 2011; Williams et al., 2002).

Research suggests that social work educators' likelihood of using service-learning is driven by their beliefs about its effect on student outcomes and their expectation of obstacles they may encounter in its implementation (Cronley et al., 2014). An even more basic problem is general confusion about what service-learning entails (Phillips, 2011). Though grounded in service, it must also include well-defined learning objectives (Rhoads, 1998).

Finally, social work educators often use the terms service-learning, volunteerism, and field practicum interchangeably (Phillips, 2011). Lack of clarity about the meaning of service-learning has hindered its development, implementation, and evaluation in social work education (Lemieux \& Allen, 2007). Phillips (2011) contended that inadequate conceptual understanding of service-learning has resulted in "social work's arrival as a late-comer to service-learning scholarship" as well as a lack of "broader disciplinary recognition of service-learning's role in supporting social work as a civically engaged discipline” (p. 9).

\section{Background for the Current Study}

It has been established that social work students often begin research courses with trepidation, viewing research as something unpleasant that must be endured in order to graduate rather than as a way to understand, develop, and/or apply evidence-based practice (Steinberg \& Vinjamuri, 2014). Applying adult-learning principles helps learners make meaning of practice-based research by integrating knowledge and skills (Daley, 2001; Layne et al., 2009; Otto, Polutta, \& Ziegler, 2009). In designing the advanced social work research course described here, the instructors adapted Layne et al.'s (2009) learning principles for research-informed practice to the process of learning to conduct practiceinformed research.

The curriculum for this required MSW-level, concentration year class featured a service-learning component involving community-based practice (a pro bono applied 
research/program evaluation project for a local non-profit agency). Students in classes offered during four consecutive years worked in task-focused small groups on courserelated activities that emphasized adult learning principles. Course topics included: (a) ethical issues in program evaluation, (b) using logic models to describe programs and their theory of change, (c) needs/assets assessment and formative/process evaluation, (d) client satisfaction and cost effectiveness, (e) qualitative/mixed methods, (f) measurement tools and strategies, (g) inferential statistics, (h) data analysis and interpretation, and (i) writing and presenting evaluation reports.

In keeping with adult learning principles as outlined by Layne et al. (2009), the study of these research concepts and skills was made relevant and problem-focused through engagement in the service-learning project, which included evaluation design, research ethics approval, participant observation, face-to-face client interviews, data entry, analysis, and reporting. Final products included a group paper, a class presentation of results to the agency's executive director and board, and peer evaluations. The service-learning project provided scaffolding for the course via a hands-on learning experience. Importantly, it offered opportunities for students to test and hone their assumptions, knowledge, and skills through engineered failure in a safe context that allowed them to learn from a direct feedback loop. Use of these adult learning principles was intended to directly promote students' development of competencies to conduct themselves as professional social workers, apply critical thinking, and engage in research-informed practice and practiceinformed research (CSWE, 2008).

A previously published quantitative exploration of course outcomes (Deck et al., 2015) suggested that this service-learning model improved students' perceived ability to perform program evaluation and research tasks skillfully, as measured by the Evaluation SelfEfficacy Scale (Holden, Barker, Rosenberg, \& Onghena, 2007, 2008). The authors, who were also course instructors, noted unmeasured but observable changes in students' mastery of core CSWE competencies related to human rights and social justice, community context, and social work practice (CSWE, 2008). Anecdotally, these seemed to result from students' meaningful, direct engagement with a vulnerable population, and from having the opportunity to directly affect program operations and community responses to this population through a hands-on experience of research and program evaluation. Content analysis of existing course-related documents was used to explore students' perceptions of the service-learning project and to gain insight into the competencies they believed they used to complete the project. These details were expected to complement the prior quantitative analysis of project outcomes by providing a deeper understanding of the process through which engaged, andragogy-based teaching methods can lead to increased research self-efficacy. Through narrative analysis of themes identified in students' written reflections on their service-learning experience, the present study aimed to provide insight into the meaning students made of the project and their perceptions of how this adult learning experience connected to their mastery of social work skills.

\section{Methods}

Data were collected between 2012 and 2015 from a convenience sample of four consecutive cohorts of MSW students who were enrolled in a required advanced research 
course in their concentration year. Over this period, the course was taught by three instructors, all of whom used the same assignment on which this study was based. In the first year, the class was conducted using a traditional face-to-face approach; subsequently, the course transitioned to a hybrid model in which some of the material was delivered online.

In all four years, the signature project for the course was a collaborative pro bono program evaluation for a non-profit agency that provides day shelter and services for homeless men. A collaborative relationship with this agency was originally established through professional connections between faculty and agency staff as well as faculty members who served on the board of directors for this agency and the local Coalition for the Homeless. Faculty worked with the executive director and other key agency staff to design the evaluation and create the survey instrument. Because the agency is required to submit an annual program evaluation to its funders, each annual survey included questions related to service utilization and client satisfaction. Additional survey items that varied each year explored characteristics, conditions, and experiences of the agency's homeless guests (i.e., trauma, access to health and mental health services, employment history, etc.). These questions were tailored to meet the agency's needs for information as they explored options for improving existing services and adding new services and staff.

\section{Sample}

In 2011-12 and 2012-13, there were two sections of the course. However, only one instructor retained copies of material submitted by students. Data were available in those years for 11 and 14 students, respectively (two students' assignments were missing for 2011-12). In 2013-14 and 2014-15, instructors for both sections retained student assignments. Material for a total of 20 students in 2013-14, and 25 students in 2014-15 was available (data were missing for four students in 2013-14 and one student in 2014-15). In summary, this study was based on narratives submitted by an unduplicated total of 70 students over a four-year period. Because narratives for the 70 students included in the study were de-identified, it is not possible to report detailed demographic characteristics. However, most students in the sampling frame $(\mathrm{n}=77)$ were female $(84.4 \%)$, and about a third (35.1\%) were African American or another racial/ethnic minority.

\section{Data Collection}

This study analyzed existing data provided by an assigned reflection paper. Because student narratives were de-identified for research purposes, the study met the criteria for exemption from ongoing review under 45 CFR 46.101(b)(1) and 45 CFR 46.101(b)(4). The Research Ethics Committee at Spalding University reviewed the protocol before the study commenced.

A challenge for practice-focused disciplines such as social work is to help students connect theoretical constructs of content to the application of direct practice. The advanced research curriculum described here concentrates on evaluation of service delivery in social work practice. Overarching goals are: 
(a) to increase graduates' use of evaluation methods by developing their confidence in their own ability to do so (via direct engagement during the course)

(b) to enhance graduates' valuing of research and program evaluation (via a direct experience of its relevance and potential impact on vulnerable populations).

The intent was to create a bridge between the classroom and the community through a hands-on experience- the service-learning project. Students were guided by faculty in designing the program evaluation, collecting and entering data, conducting analyses, interpreting findings, and reporting results. During one or more visits to the local day shelter, each student completed participant observation and one-to-one interviews with homeless men. After entering data into a password-protected, encrypted online database, small groups of students worked together to analyze and report findings for topicallyrelated subsets of data items. Ultimately, these results were combined into a single, formal presentation to the agency's executive director and board members, which subsequently informed the agency's strategic planning efforts.

This project afforded students a contextual learning opportunity shaped by the core competencies. A written assignment offered a chance for individual reflection on the service-learning component of the course, and was also the basis for shared reflection during in-class discussion. The instructions for the assignment prompted students to link their experience to identified competencies. They were encouraged to offer a meaningful response, but were given no other constraints or parameters. The following questions were used consistently by each instructor over the four-year period of the project:

(a) How has the service-learning project impacted your thinking, either positively or negatively, about the homeless population? Discuss two specific examples.

(b) Discuss three (of the ten) Council on Social Work Education (CSWE) competencies that you have found most useful in completing service-learning activities such as instrument design/review, Research Ethics Committee application, conducting interviews, completing participant observation, writing a literature review, etc. Explain why these competencies were most useful.

Reflection papers were due at the end of the data collection period, and were worth up to five percent of the total points available for the course.

\section{Data Analysis}

Shank (2002) defined qualitative research as a "systematic, empirical inquiry into meaning” (p. 11). In this study, the investigators aimed to gain a detailed, textured understanding of the meaning students made of the service-learning project, as well as the connections they made between this experiential learning activity and the formal social work curriculum. This understanding emerged inductively from close examination of student responses in their own authentic voice.

To establish credibility, all student papers were typed verbatim into electronic files using Microsoft Word, and were identified only by the instructor's name, the year 
completed, and a sequential student identification number. Two investigators (one of whom had not been an instructor in this course) analyzed the content of these narratives using open coding to determine themes and patterns in responses to the two questions. Consultation with the third investigator, the principal instructor for the course, was used to make decisions about the coding process and to define concepts more precisely. Through triangulation and peer debriefing, the investigators checked their perceptions and understanding of the data, probing for perspectives and biases that might otherwise remain unknown (Lincoln \& Guba, 1985).

\section{Findings}

Content analysis of students' narratives revealed three main themes. First, students perceived that they had changed their thinking about homelessness in positive ways. Second, students made connections between their experience, the social work curriculum, and the requisite areas of competency in predictable as well as unexpected ways. Finally, an unanticipated theme of integration emerged.

\section{Impact of the Service Learning Project}

The first part of the assignment invited students to reflect on whether they believed the service learning experience had a positive or negative effect on their thinking about homeless persons. Across all four years, students consistently identified their experiences as positive, and described how the service-learning project helped them apply theory to practice. As an example, one student acknowledged beginning the project with a sense of pity for homeless persons who were presumed to be "drunks" and people with "mental issues." This student articulated how direct connections with men at the shelter had changed the student's perceptions:

This learning experience has been a unique one. My personal and professional world has been stretched more than I thought it would from five simple interviews, a literature review, an observation, and preparing a presentation. It challenged my thoughts and helped me to see how much context affects my practice. It was a beautiful reminder that practice must constantly evolve just like the field of social work does.

Another student referenced concerns about the project prior to its execution, stating that she had been "fearful" of the interview process. She then reflected on benefits of the experience and the ways it affected her perspective on the engaged population:

Before visiting [the center], I had never met a homeless person. I was never able to hear the struggles firsthand. I think a lot of people assume that someone who is homeless is probably uneducated, mentally ill, or a substance abuser. People forget that these individuals are human beings with feelings, and intelligence, and a desire to get help, yet they often don't have the resources to do so. It's hard to think otherwise without hearing from individuals firsthand. This experience opened my eyes, helped remind me of the importance of social justice, and reinforced my belief that all individuals should be treated with fairness and respect. 
A few participants believed the experience had a "negative" effect, but only in the sense that they became more aware that homelessness among veterans and/or adult men is a reality in their own and other communities.

\section{Curriculum and Competency Connections}

A second question asked students to identify competencies they developed during the project. Over the four-year period, each of the ten CSWE competencies was acknowledged by at least two students. The five most commonly mentioned competencies or skill areas were research, professional use of self, social justice, equity, and diversity.

The most frequently named competency was research-informed practice and practiceinformed research. This was followed closely by professional use of self (i.e., attending to roles and boundaries, advocating for clients, practicing personal reflection, etc.). As the project clearly required both, these were intended and expected responses. However, many students also made connections between research- and practice-related competencies. For example, one student said,

Research has informed my practice and practice has informed my research. Having worked with homeless women...last year, I was able to do a significant amount of research to inform my practice. Through approaching this research into practice, I was able to learn a lot about myself and delivering my services. I was able to witness this knowledge and wisdom gained from my own practice in this service-learning project.

The prevalent discussion of three additional concepts speaks to a secondary gain of the project. The frequency of mentions of social justice, equity, and diversity was separated by only one response from the top two themes. Though each of the three is considered a foundational element of both social work practice and social work education, they are not concepts that are traditionally linked to research (or explicitly taught in research courses). In this course experience, students resonated with the concept of research as a practice tool that supports work for social justice and equity.

Diversity was framed primarily with a focus on homelessness as a category of difference. Although the men they interviewed were racially diverse, students were particularly impacted by the causes and implications of homelessness that they heard described directly by those who are affected. One student explained:

[Being able to engage with diversity and difference in practice] allows for stereotypes to be minimized. Seeing a wide age range, historical backgrounds, ethnic differences, and experiences is what allows for more effective services to be implemented as it allows for a larger population to be served and service providers to be knowledgeable about.

It warrants acknowledging that approximately 15 percent of students responded to the question about competencies they used in the project by describing their own intrinsic strengths or abilities rather than discussing the CSWE competencies as instructed in the prompt for the assignment. However, a thematic analysis of these responses revealed that 
mentions of personal strengths and skills used to accomplish project tasks were clearly expressions of the top five competencies as identified by the other participants.

\section{Integrated Practice}

The discussion of competencies within a practice setting reflected an unanticipated yet tangible experience of integrated practice for participating students. The connections between skills, context, and community were evidenced not only by the acknowledgement of research and professional use of self as key competencies, but also in the exploration of how these were applied. In the process of using interviewing skills, for example, the implications of context and community became quite real. One student noted a clear interrelationship between direct practice, research, advocacy, and social change strategies:

Every one of the [five] men that I interviewed had been diagnosed or said they knew that they had mental illness. You read articles and it is common knowledge in our field that this is a big [precursor] to becoming homeless, but actually sitting down and talking to the men really had an impact on me. It made me feel that maybe there was something that I could help with or be a part of to empower these men living with mental illness, and that is exactly what this survey is meant for.

Student responses further indicated the application of effective engagement skills to ensure successful completion of the project. That is, practice skills were integral to the research process (and were improved by participating in the project). Likewise, research skills were experienced as an equally integral part of ethical social work practice as opposed to a tool that is only employed by program evaluators and scientists. In other words, the nebulous, theoretical construct of integrated practice became real and relevant in its application. The impact on students is portrayed in this passage from one student's narrative:

One example I recall [of how my thinking changed] was when I was actually conducting the interviews. When we got to the last question, the gentleman told me that we need to know what it is to be homeless and not just doing a survey, or whatever we do. The gentleman explained that he was not that educated but unless you have lived every day in a homeless shelter for at least two months you don't understand. I told the gentleman he was right, many of us do not know what it is really like, and I was sorry for that. I also explained that we do care, and want to do better. What I took from this is that we really don't know what it is like... [It] is more than just learning all the stuff related to homelessness or research. There are experiences, feelings that become a part of who you are.

In describing competencies developed through the service-learning project, this student noted that strengthening her ability to engage in research-informed practice "helped me see just how vulnerable and oppressed homeless men were and their culture of marginalization and repeated trauma." 


\section{Discussion}

The service-learning approach for this graduate-level research course was associated with significant increases in students' self-efficacy related to research and program evaluation skills (Deck et al., 2015). Importantly, through a process of reflecting on the experience, students also described changes in their knowledge, values, and skills in other areas of the social work curriculum. Reflection helps students to "gain further understanding of course content, a broader appreciation of the discipline, and an enhanced sense of civic responsibility" (Bringle \& Hatcher, 2002, p. 505) by providing an opportunity to think, feel, and do things differently and to make connections between inclass learning and experiential learning outside the classroom (Campbell, 2012). Jacoby (1996) emphasized that direct experiences are necessary, but not sufficient, for learning and development to occur. Rather, it is reflection that explicitly fosters these servicelearning outcomes.

\section{Effects of Reflection}

For the four cohorts of students in this study, the service-learning project clearly opened a door to new perceptions of research (Campbell, 2012). Yet, students went beyond this in their comments. Reflection-in writing as well as discussion with instructors and peers who shared the experience-gave them insight into ways that the research project connected to many other curriculum areas. Because they moved from concrete experience and reflective observation to abstract conceptualization, students could link their realworld experiences to content they had previously learned in other classes (Kolb, 1984). As evidenced by their narrative responses, they could envision ways to actively experiment with newfound understanding (e.g., notice "how much context affects my practice," "constantly evolve" practice, treat all individuals "with fairness and respect," "empower these men living with mental illness," and so on). Coulshed (1993) described this process as meta-learning, or developing higher reasoning and critical thinking abilities that helps make it possible for students to continue to apply knowledge they gain in future practice.

One particularly important finding of this study is that new knowledge and skills gained in this course were meaningful to students. A constructivist perspective on learning suggests that educational activities should help students integrate thinking, feeling, and behavior. Daley's (2001) study of how knowledge becomes meaningful in practice for various professions including social work found that interaction with clients was often central to the process, especially if this involved an emotional encounter and/or challenged a practitioner's existing knowledge, beliefs, or assumptions. Reflection is central to processing experiences, exploring meaning, and deepening understanding. Daley (2001) noted that powerful and memorable client encounters often lead professionals to restructure their work.

In the current study, significant—and often emotional-interactions with homeless men elicited meaningful shifts in students' perspectives and their orientation to professional practice (e.g., their personal and professional worlds were "stretched," thinking was "challenged," eyes were "opened," and students gained "wisdom” by learning about themselves as this related to "delivering my services"). In other words, students 
expressed awareness of how the service-learning project affected and changed them (Yorio \& Ye, 2012).

Students also developed personal insight into social issues such as homelessness, mental illness, diversity, and oppression. Yorio and Ye (2012) proposed that "selfrevealing information, activated through the process of reflection, can become a source of self-development” (p. 12). This, in turn, affects students' self-definition (i.e., "I was able to learn a lot about myself" and "actually sitting down and talking to the men really had an impact on me"), as well as their perception of themselves as leaders with a civic responsibility (i.e., "It made me feel that maybe there was something that I could help with or be a part of").

Finally, the opportunity for immediate and real application of research knowledge and skills learned in the classroom changed their meaning for students. That is, information, theory, and techniques became more relevant. Reflection and structured discussions developed students' awareness of linkages between their service activities and educational outcomes. Steinberg and Vinjamuri (2014) noted that such reflection and discussion are "particularly useful in helping students who can articulate the relevance of research principles but have difficulty connecting this material to actual practice," as well as those who "are quick to apply content but have difficulty grasping the nuances of important research constructs” (p. 375).

The fact that this service-learning project required individual activities as well as smalland large-group collaboration may have contributed to the positive outcomes in this research course. Talking with members of peer groups can challenge assumptions, increase awareness of other perspectives, and enlarge each member's point of view (Coulshed, 1993; Steinberg \& Vinjamuri, 2014). Students with varying aptitudes in elements of the research process could learn these skills by observing one another in real time. Lastly, working in small groups may have helped students who were anxious about the course to find mutual support through a shared experience (Steinberg \& Vinjamuri, 2014).

\section{Development of Social Work Competencies}

Research. The finding that using service-learning supported students' development and application of social work research skills aligns with other studies (Anderson, 2000; Harder, 2010; Hyde \& Meyer, 2004; Kapp, 2006; Knee, 2002). In a general sense, servicelearning has empirically demonstrated effects on academic learning, including cognitive development, critical thinking, and application of skills (Cronley et al., 2014; Phillips, 2011; Williams et al., 2002; Yorio \& Ye, 2012). Eyler and Giles (1999) explained that the observed positive effects of service-learning on cognitive development (including writing and problem-solving skills, critical thinking, and course performance) are a function of three factors: (a) students' increased motivation to address community problems, (b) realworld opportunities to test theories and deepen understanding by directly applying knowledge and skills, and (c) exposure to others who are different. Indeed, students in this course spoke of the importance of being able to directly and actively witness the ways that practice informed their research and research informed their practice. 
Professional use of self. The literature also supports the notions that service-learning positively affects students' personal and moral development as well as their sense of personal efficacy (Cronley et al., 2014). Yorio and Ye (2012) referred to this outcome as development of personal insight, which encompasses identity, awareness of one's strengths and weaknesses, professional aspirations, self-efficacy, self-esteem, persistence, and determination. They underscored the importance of reflection and social interactioninherent in service-learning - in the enhancement of personal insight.

Williams et al. (2002) used Bandura's (1997) self-efficacy theory to explain the underlying process of self-development. Self-efficacy, or a belief in one's own capability, depends upon how students perceive their experience, the role they play in the learning process, and the meaning they assign to this process. Service-learning involves students more directly in the learning process, and reflection supports them in noticing their perceptions and creating meaning. Self-efficacy theory proposes that these conditions, in combination with experiences of agency and mastery, lead to generalizable performance expectancies, which are further associated with motivation, persistence, an ability to make decisions and set goals, and willingness to engage in learned tasks in the future. In other words, as one student in this study said, this project involved "more than just learning all the stuff related to homelessness or research. There are experiences, feelings that become a part of who you are.”

Social justice, equity, and diversity. Research on service-learning outcomes reveals positive effects on students' cultural competency, understanding of social issues, and civic engagement (Cronley et al., 2014; Phillips, 2011; Williams et al., 2002; Yorio \& Ye, 2012). Yorio and Ye's (2012) conceptualization of understanding social issues as a learning outcome included students' diversity/cultural awareness, perceptions of marginalized groups, ethical/moral decision-making, understanding of how to meet community needs, and commitment to the responsibilities of citizenship. Coulshed (1993) argued that adult learners who confront uncertainty, as well as their own and others' divergent assumptions about the nature of human behavior in social environments, may progress through confusion to arrive at a deconstruction of their own over-simplified thinking. While diversity and difference can be conceptually approached in the classroom, the experience of entering an unfamiliar place and functioning in an unfamiliar role-as students did in this project—can deepen social awareness, promote empathy, and increase tolerance and appreciation of persons who are different from oneself (Williams et al., 2002; Yorio \& Ye, 2012).

Building relationships with community partners, gaining a deeper understanding of social issues, and cultivating moral awareness can stimulate an understanding of and commitment to social justice (Yorio \& Ye, 2012). In this sense, service-learning is consonant with the values and principles of the social work profession. Phillips (2011) asserted that many scholars and practitioners see service-learning as a tool for social transformation. However, some have expressed concern that traditional service-learning approaches that position the university as a source of expertise and benevolence, and/or reinforce stereotypes and the status quo, do not align with the social work profession's emphasis on strengths, empowerment, challenging privilege and oppression, and being client-centered (Donaldson \& Daughtery, 2011; Phillips, 2011). In one survey of social 
work educators about perceived effects of service-learning, respondents were least likely to say that service-learning "has the explicit social justice aim of dismantling structures of inequality” (Cronley et al., 2014, p. 161). When power and privilege are imbalanced among service providers and recipients, and self-determination is neglected, service-learning may undermine rather than promote social justice.

Donaldson and Daughtery (2011) advocated for progressive service-learning models that involve service recipients in defining problems, identifying priorities, and making decisions, and that reinforce their existing and potential strengths and capabilities. Servicelearning experiences that emphasize social work values should also lead students to question the distribution of power and resources. Students involved in the service-learning project presented in this study made these connections, noting that "empowering these men” was "exactly what this survey [was] meant for."

Asserting that "if we are to promote democratic citizenship in these challenging times, then we must foster in our citizens a commitment to caring," Rhoads (1998) expressed a critical point: "Higher education has a major part to play in this process, and involving students in community service may be one vehicle for meeting this challenge” (p. 283). Rhoads argued that development of positive regard for self and others is transactional, and that fostering relationships with diverse others through personalized service and meaningful interaction can heighten one's ability to care. In this project, a commitment to serving and caring was most powerfully expressed by the student who acknowledged an inability to completely understand the experience of homelessness and expressed a desire to do better.

\section{Integrated Practice}

Shannon et al. (2012) argued that widespread student dissatisfaction with social work research courses is due to the failure of these courses to incorporate research consumption, production, and integration outcomes, and the authors concluded that "demonstrating the usefulness of research to social work students through service learning projects [provides]... a more integrated experiential strategy” (p. 231). Similarly, Steinberg and Vinjamuri (2014) maintained that when students believe that research skill development will improve their practice, their anxiety about research courses can be neutralized.

A positive, yet unanticipated, outcome of this service-learning project was the depth of integration students described. As commonly taught, social work research is often esoteric and isolated from other areas of the core curriculum (Kapp, 2006; Shannon et al., 2012; Steinberg \& Vinjamuri, 2014). However, students involved in this project not only described connections between research and practice, they also noticed how they had incorporated other areas of the social work curriculum.

In response to CSWE's requirement to integrate research with practice, social work programs have experimented with situating integration efforts within a course, embedding integration experiences in practicum, and even overhauling the entire curriculum (Kapp, 2006). Some have incorporated a weaving session (Colby, 2013) or transfer seminar (Coulshed, 1993) to support students in synthesizing content across courses or the curriculum. Coulshed (1993) referred to this metacognitive process as an opportunity for 
expanded learning. As expressed by students in this study, a service-learning experience in the advanced research course promoted reflection on their learning process and an active experience of weaving together all or many of the social work competencies.

\section{Conclusion}

In summary, students who participated in a graduate-level research course with a service-learning project as the primary teaching-learning experience described learning outcomes in many domains that extended beyond the traditional, bounded content of social work research courses. Furthermore, through the process of reflection-which is inherent in service-learning - students integrated their experiences in ways that allowed them to synthesize and apply knowledge, values, and skills that are often fragmented among social work graduates. This was not an incidental byproduct of service-learning, but rather an outcome that can be explained by adult learning theory (Kolb, 1984). Concrete experience and reflective observation are the sine qua non of service-learning, and the fact that they lead to abstract conceptualization and active experimentation is exactly what adult learning theory predicts.

To date, the literature related to application and evaluation of service-learning in social work is underdeveloped and should be further explored (Cronley et al., 2014; Phillips, 2011; Williams et al., 2002). This study contributes to that process in that it expresses-in students' own words - the meaning made of a service-learning experience and the ways it affected their perception of knowledge, values, and skills. One participating student concluded that "it was a beautiful reminder that practice must constantly evolve just like the field of social work does." It is to this explicit evolutionary challenge that social work educators are called.

\section{References}

Anderson, S. (2000). Engaging students in community-based research: A model for teaching social work research. Journal of Community-Based Practice, 10(2), 71-87. doi: https://doi.org/10.1300/J125v10n02_05

Averett, P. E., \& Arnd-Caddigan, M. (2014). Preparing BSW students for servicelearning: Enhancing epistemological reflection. Journal of Teaching in Social Work, 32(3), 316-331. doi: https://doi.org/10.1080/08841233.2014.907222

Bandura, A. (1997). Self-efficacy: The exercise of control. New York: Freeman.

Bringle, R. G., \& Hatcher, J. A. (1995). A service-learning curriculum for faculty. The Michigan Journal of Community Service-Learning, 2, 112-122.

Bringle, R. G., \& Hatcher, J. A. (2002). Campus-community partnerships: The terms of engagement. Journal of Social Issues, 58(3), 503-516. doi: https://doi.org/10.1111/1540-4560.00273

Butin, D. W. (2006). The limits of service-learning in higher education. Review of Higher Education, 29(4), 473-498. doi: https://doi.org/10.1353/rhe.2006.0025 
Campbell, E. M. (2012). Implementing service learning into a graduate social work course: A step-by-step guide. Journal of Teaching in Social Work, 32(3), 300-313. doi: https://doi.org/10.1080/08841233.2012.688935

Colby, I. C. (2013). Rethinking the MSW curriculum. Journal of Social Work Education, 49, 4-15.

Coulshed, V. (1993). Adult learning: Implications for teaching social work education. The British Journal of Social Work, 23(1), 1-13.

Council on Social Work Education [CSWE]. (2008). Educational Policy and Accreditation Standards. Alexandria, VA: Author.

CSWE. (2015). 2015 Educational policy and accreditation standards for baccalaureate and master's social work programs. Alexandria, VA: Author.

Cronley, C., Madden, E., Davis, J., \& Preble, K. (2014). Factors influencing servicelearning utilization in social work: Results from an online survey of faculty. Journal of Teaching in Social Work, 34(2), 147-166. doi: http://dx.doi.org/10.1080/08841233.2014.890692

Daley, B. J. (2001). Learning and professional practice: A study of four professions. Adult Education Quarterly, 52(1), 39-54. doi: https://doi.org/10.1177/074171360105200104

Deck, S. M., Platt, P. A., \& McCord, L. (2015). Engaged teaching-learning: Outcome evaluation for social work students in a graduate-level service learning research course. Advances in Social Work, 16(2), 233-248. doi: https://doi.org/10.18060/18302

Donaldson, L. P., \& Daughtery, L. (2011). Introducing asset-based models of social justice into service learning: A social work approach. Journal of Community Practice, 19(1), 80-99. doi: https://doi.org/10.1080/10705422.2011.550262

Edmond, T., Megivern, D., Williams, C., Rochman, E., \& Howard, M. (2006). Integrating evidence-based practice and social work field education. Journal of Social Work Education, 42(2), 377-396. doi: https://doi.org/10.5175/JSWE.2006.200404115

Epstein, I. (1987). Pedagogy of the perturbed: Teaching research to the reluctants. Journal of Teaching in Social Work, 1(1), 71-89. doi: https://doi.org/10.1300/J067v01n01_06

Eyler, J., \& Giles, D. E. (1999). Where's the learning in service-learning? San Francisco, CA: Jossey-Bass.

Gambrill, E. (1999). Evidence-based practice: An alternative to authority-based practice. Families in Society, 80, 341-350. doi: https://doi.org/10.1606/1044-3894.1214

Hardcastle, D. A., \& Bisman, C. D. (2003). Innovations in teaching social work research. Social Work Education, 22(1), 31-43. doi: https://doi.org/10.1080/02615470309131 
Harder, J. (2010). Overcoming MSW students' reluctance to engage in research. Journal of Teaching in Social Work, 30(2), 195-209. doi: https://doi.org/10.1080/08841231003705404

Holden, G., Barker, K., Rosenberg, G., \& Onghena, P. (2007). Assessing progress toward accreditation related objectives: Evidence regarding the use of self-efficacy as an outcome in the advanced concentration research curriculum. Research on Social Work Practice, 17(4), 456-465. doi: https://doi.org/10.1177/1049731506297474

Holden, G., Barker, K., Rosenberg, G., \& Onghena, P. (2008). The Evaluation SelfEfficacy Scale for assessing progress toward CSWE accreditation-related objectives: A replication. Research on Social Work Practice, 18(1), 42-26. doi: https://doi.org/10.1177/1049731507303954

Hyde, C. A., \& Meyer, M. (2004). A collaborative approach to service, learning, and scholarship: A community-based research course. Journal of Community Practice, 12(1), 71-88. doi: https://doi.org/10.1300/J125v12n01_06

Jacoby, B. (1996). Service-learning in higher education: Concepts and practices. San Francisco, CA: Jossey-Bass.

Kapp, S. A. (2006). Bringing the agency to the classroom: Using service-learning to teach research to BSW students. Journal of Baccalaureate Social Work, 12(1), 56-70.

Knee, R. T. (2002). Can service learning enhance student understanding of social work research? Journal of Teaching in Social Work, 22(1-2), 213-225.

Knowles, M. S., Holton, E. F., \& Swanson, R. A. (2005). The adult learner (6th ed.). Burlington, MA: Elsevier Butterworth-Heinemann.

Kolb, D. A. (1984). Experiential learning: Experience as the source of learning and development (Vol. 1). Englewood Cliffs, NJ: Prentice-Hall.

Layne, C. M., Fields, P. J., Moyse-Steinberg, D., Krishna, M., \& Dinov, I. (2009, November). Making evidence-based practice user friendly: Integrating clinical proficiency and data-proficiency training across the social work curriculum. In V. S. (Chair), Preparing graduate social work students for evidence-based trauma intervention. Symposium presented at the annual meeting of the Council on Social Work Education, San Antonio, TX.

Lemieux, E. M., \& Allen, P. D. (2007). Service learning in social work education: The state of knowledge, pedagogical practicalities, and practice conundrums. Journal of Social Work Education, 43(2), 309-325. doi: https://doi.org/10.5175/JSWE.2007.200500548

Lincoln, Y. S., \& Guba, E. G. (1985). Naturalistic inquiry. Newbury Park, CA: Sage.

National and Community Service Act of 1990. 42 U.S.C. §12511.

National Association of Social Workers. (2008). Code of Ethics. Washington, DC: Author. 
Otto, H., Polutta, A., \& Ziegler, H. (2009). Reflexive professionalism as a second generation of evidence-based practice: Some considerations on the special issue, 'What works? Modernizing the knowledge-base of social work'. Research on Social Work Practice, 19(4), 472-478. doi: https://doi.org/10.1177/1049731509333200

Phillips, A. (2011). Service-learning and social work competency-based education: A 'goodness of fit'? Advances in Social Work, 12(1), 1-20.

Rhoads, R. A. (1998). In the service of citizenship: A study of student involvement in community service. The Journal of Higher Education, 69(3), 277-297. doi: https://doi.org/10.1080/00221546.1998.11775135

Robinson, M. A., Robinson, M. B., \& McCaskill, G. M. (2013). Teaching note--An exploration of team-based learning and social work education: A natural fit. Journal of Social Work Education, 49, 774-781.

Rocha, C. (2000). Evaluating experiential teaching methods in a policy practice course: The case for service-learning to increase political participation. Journal of Social Work Education, 36(1), 53-56.

Shank, G. D. (2002). Qualitative research: A personal skills approach. Columbus, ON: Merrill Prentice Hall.

Shannon, P., Kim, W., \& Robinson, A. (2012). Implementing a service learning model for teaching research methods and program evaluation. Journal of Teaching in Social Work, 32(3), 229-242. doi: https://doi.org/10.1080/08841233.2012.680867

Steinberg, D. M., \& Vinjamuri, M. K. (2014). Activating adult-learning principles through small groups in preparing social work students to achieve CSWE research competencies. Journal of Teaching in Social Work, 34(4), 363-383. doi: https://doi.org/10.1080/08841233.2014.937890

Thyer, B. (2004). What is evidence-based practice? Brief Treatment and Crisis Intervention, 4, 167-176.

Wells, M. (2006). Teaching notes: Making statistics "real" for social work students. Journal of Social Work Education, 42(2), 397-404. doi: https://doi.org/10.5175/JSWE.2006.200400466

Williams, N. R., King, M., \& Koob, J. J. (2002). Social work students go to camp. Journal of Teaching in Social Work, 22(3-4), 55-70. doi: https://doi.org/10.1300/J067v22n03_05

Yorio, P. L., \& Ye, F. (2012). A meta-analysis on the effects of service-learning on the social, personal, and cognitive outcomes of learning. Academy of Management Learning and Education, 11(1), 9-27. doi: https://doi.org/10.5465/amle.2010.0072

Author note: Address correspondence to: Stacy M. Deck, PhD, MSSW, Spalding University School of Social Work, 545 South 3rd Street, Louisville, KY 40203. Email: sdeck@spalding.edu 